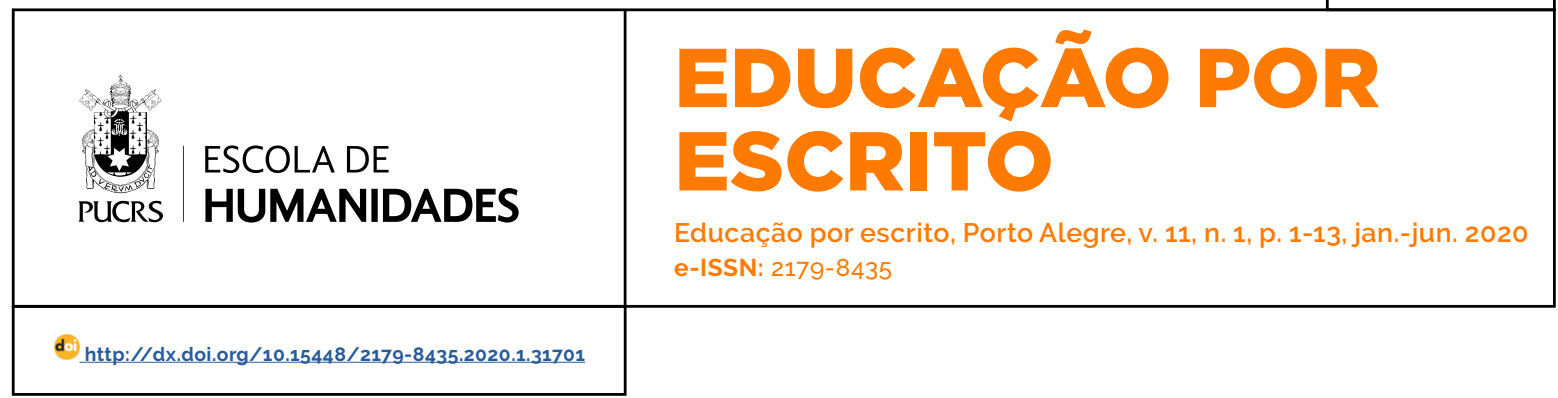

SEÇÃO ARTIGOS

\title{
Diálogos sobre o bullying escolar e o desenvolvimento humano
}

\author{
Dialogues on school bullying and human development
}

\section{Michelle Popenga \\ Geraim Monteiro ${ }^{1}$}

orcid.org/0000-0003-3058-8987

mizinhadobru@yahoo.com.br

Araci Asinelli-Luz orcid.org/0000-0001-5880-0543 araciasinelli@hotmail.com

Recebido em: 16 ago. 2018. Aprovado em: 8 jan. 2020. Publicado em: 27 jul. 2020
Resumo: Este trabalho destaca o bullying escolar e suas implicações no desenvolvimento humano. O artigo originou-se de uma pesquisa de mestrado em educação que investigou a percepção do bullying junto a duas turmas de quinto ano do Ensino Fundamental, envolvendo 38 estudantes com idades entre 9 e 11 anos, meninos e meninas. A análise dos dados deste presente estudo é de natureza qualitativa. Para a coleta de dados utilizou-se um questionário semiestruturado com 26 questões. Mostraram-se relevantes ao estudo questões relacionadas ao fenômeno e suas implicações no desenvolvimento humano, podendo afirmar que a escola, da forma como estabelece as relações interpessoais, pode ser entendida como um microssistema onde a violência também se manifesta como bullying. como sintoma da violência social na escola. Acredita-se que o microssistema escola é necessário ao desenvolvimento humano, acolhendo e respeitando os estudantes vitimizados, encorajando a Cultura de Paz e não violência.

Palavras-chave: Bullying. Ensino Fundamental. Violência escolar. Educação.

Abstract: This work highlights school bullying and its implications for human development. The article originated from a master's degree research in education that investigated the perception of Bullying in two fifth-year classes of Primary Education, involving 38 students between 9 and 11 years old, boys and girls. The analysis of the data of this present study is qualitative in nature. A semistructured questionnaire with 26 questions was used to collect data. Issues related to the phenomenon and its implications for human development have been relevant to the study, and may affirm that the school, as it establishes interpersonal relations, can be understood as a microsystem where violence is also manifested as bullying as a symptom of violence social at school. It is believed that the school microsystem is necessary for human development, welcoming and respecting victimized students, encouraging a culture of peace and non-violence.

Keywords: Bullying. Elementary School. School violence. Education.

\section{Introdução}

O desenvolvimento humano se define pelo estudo das mudanças no ser humano que acontecem desde a fecundação, com ênfase na fase do nascimento até a morte. Ele pode ser compreendido como complexo pelo fato de as mudanças ocorrerem em todas as dimensões no individuo, interdependentes e que se interconectam entre si. O desenvolvimento do individuo está sujeito a mudanças exercidas pela hereditariedade, pelo ambiente, pelo estilo parental, pela cultura, pela condição socioeconômica, entre outros (PAPALIA; OLDS, 2000). 
O estudo da Terceira Infância, também chamado de anos escolares, recebe essa segunda nomenclatura porque a escola é o microssistema ${ }^{2}$ onde a criança passa grande parte de seu dia, durante anos, em interação com outras crianças e adultos de referência (professores). Portanto, a escola é de importância para o desenvolvimento humano nas dimensões biopsicossociais, com ênfase no desenvolvimento cognitivo-acadêmico, cultural e relacional. Para muitas crianças (as de classes sociais menos favorecidas), a escola é o único microssistema determinante para seu desenvolvimento, além do microssistema familiar. Para este estudo, destacou-se esse período por relacionar-se aos participantes da pesquisa, dando-se destaque ao desenvolvimento da moralidade, na perspectiva de Jean Piaget.

Nessa etapa do desenvolvimento, as crianças desenvolvem-se com maior intensidade nas dimensões físicas, psicológicas, sociais, cognitivas, emocionais e morais que as possibilitam empreenderem atividades mais elaboradas e complexas. Há avanços significativos no pensamento, no juizo moral, na memória, leitura e escrita das crianças, com repercussões importantes na autoestima. As crianças adquirem também maior tamanho, rapidez e coordenação em suas habilidades motoras (PAPALIA; OLDS, 2000).

É no microssistema escola, cenário recheado de pessoas e suas inter-relações em desenvolvimento, que se manifesta o bullying: considerado um fenômeno sistêmico que envolve diversas pessoas e ambientes, por meio de atitudes agressivas, premeditadas, repetitivas e entre pares, e que por meio dos estudos realizados nos últimos tempos por pesquisadores de vários lugares do mundo, têm evidenciado que o fenômeno está presente no cotidiano de muitas escolas, caracterizando-se por um problema real e grave para muitas crianças, e que ainda é sutile velado, dificultando ainda mais a identificação do mesmo. Portanto, pensar a violência na sociedade e nas escolas é uma questão importante e urgente; principalmente quando se evidencia que a escola é o segundo ambiente, depois do familiar, de maior convívio das crianças e responsável, em grande parte, pela sua socialização. Portanto, o ambiente escolar é permeado pelas relações interpessoais e é nesse microssistema que elas se intensificam, pois há uma maior concentração de pessoas em relação ao ambiente familiar. Assim, devido à intensificação dessas relações, as crianças podem ou não aprender a resolver seus problemas e conflitos, que acontecem com bastante frequência entre os estudantes. A construção dos sujeitos, portanto, envolve as relações interpessoais, bem como a trama de relações favorecidas ou não nos microssistemas do desenvolvimento humano (OLIVEIRA; GOMES, 2012; TIMM, 2012; MONTEIRO, 2017).

Diante disso, pode-se compreender a escola como um dos espaços de manifestações de violência, particularmente o bullying, e que a sua superação pode ser realizada por meio de mudanças comportamentais e ambientais. Por isso, o objetivo deste artigo é dialogar sobre o bullying escolar e suas relações com o desenvolvimento humano, com fins de colaborar com os estudos voltados ao tema, sendo possivel assim a criação de medidas preventivas que auxiliem na mediação e na superação do fenômeno nas escolas.

\section{Abordagens teóricas}

A abordagem de Jean Piaget e a Teoria da Moral

Em relação à educação escolar e aos movimentos pedagógicos, a perspectiva psicogenética de Jean Piaget é ainda a corrente que orienta a organização teórica e pedagógica nas escolas, de modo geral. A terceira infância é caracterizada pelas crianças que entram no Estágio de Desenvolvimento Cognitivo: as operações concretas. Elas apresentam um menor nivel de egocentrismo e podem resolver problemas concretos. Elas pensam de forma lógica, pois conseguem analisar vários aspectos

\footnotetext{
2 Microssistema é o termo utilizado pela Teoria Bioecológica como sendo o ambiente de maior contato e mais próximo do indivíduo em desenvolvimento- como a familia e a escola, por exemplo.
} 
de uma situação. Entretanto, elas ainda estão limitadas a resolverem apenas situações hipotéticas (PAPALIA; OLDS, 2000; MOREIRA, 1999; MONTEIRO, 2017). O modelo criado por Piaget para demonstrar o desenvolvimento cognitivo da criança por meio de etapas corresponde às características de sua época. Embora ainda validado, suas premissas têm gerado discussões em decorrência dos impactos da atualidade, como as midias, as redes sociais e as tecnologias que têm tornado o desenvolvimento da criança mais apurado ou mais lento, dependendo do estímulo que ela recebe.

Por compreender-se o bullying como uma das formas de violência na escola, acredita-se que os estudos da moralidade auxiliam a analisar melhor esse fenômeno. Para Piaget, o julgamento moral está relacionado ao desenvolvimento cognitivo das crianças que, nessa fase da vida, a terceira infância, podem fazer julgamentos de forma concreta, analisando diversos pontos de vista de uma mesma situação. Em um primeiro momento do desenvolvimento, há a moralidade de restrição, o pensamento é resistente, ou seja, há apenas uma forma certa e uma forma errada - apenas uma maneira de se considerar uma situação. Após, a moralidade da cooperação, a criança apresenta plasticidade e maleabilidade em seu julgamento moral. As crianças interagem com mais indivíduos, outras crianças e adultos, elas ganham maior capacidade de entender as situações que vivenciam. Elas combinam a experiência vivida com a maturidade que está se desenvolvendo cognitivamente e formulam novas ideias de moralidade (PIAGET, 1994; PAPALIA; OLDS, 2000; MONTEIRO, 2017).

Piaget ampliou a sua teoria sobre a moral a partir dos jogos de regras. Por meio deles, ele pode observar o comportamento das crianças diante do jogo e a relação de moralidade e respeito estabelecida entre os pares. Em suas palavras "toda moral consiste num sistema de regras e a essência de toda moralidade deve ser procurada no respeito que o indivíduo adquire por estas regras" (PIAGET, 1994, p. 23). Portanto, por analogia, pode-se inferir que o bullying cresce em um ambiente onde não se encontra respeito mútuo e uma dinâmica saudável de relacionamentos. As regras são quebradas e há um desequilibrio de poder.

Ao longo do ciclo vital, a criança fortalece seu senso de moral e justiça que é latente. Quando nasce, o bebê é ausente de regras. Conforme a criança cresce vai experimentando as regras colocadas pelo meio em que vive com a mediação dos adultos, até chegar ao nivel de autonomia, internalizando o juizo que agora the é próprio. Ou seja, da anomia à heteronomia, até atingir a autonomia (MONTEIRO, 2017). Na fase dos sete aos onze anos, a criança obedece às regras, mas destitui o valor sagrado dado a elas. Para Piaget, o ideal moral ancora o principio de justiça, ou seja, é preciso "enxergar o 'sujeito psicológico' do outro" (TOGNETTA, 2003, p. 37).

Assim, um adulto pode cooperar com a construção da moral e do senso de justiça da criança quando ele pratica a reciprocidade e minimiza seu poder de decisão, deixando a criança participar como sujeito ativo na elaboração desses elementos. A criança passa a observar inúmeras possibilidades de respeitar o outro e estabelece princípios que a torna mais criteriosa e exigente em seus juizos (PIAGET, 1994; TOGNETTA, 2003).

A experiência da criança na fase escolar é fundamental para o desenvolvimento humano. Cada criança explora novas habilidades físicas, comportamentais e emocionais que a auxilia a atingir maior sucesso em sua vida estudantil. Os estilos parentais e o modelo sociocultural em que a criança está inserida também são pilares para o desenvolvimento. As relações estabelecidas pela familia e pela sociedade podem induzir a forma como ocorrerão as mudanças no indivíduo. Os pais podem colaborar por meio de estímulo aos seus filhos no envolvimento com as questões escolares e na participação desses. Na terceira infância, a criança deixa de ser egocêntrica, seu emocional fica mais acessivel e permissivo, compartilhando sentimentos com seus pares. Ela pode se tornar mais empática e sociável. Por essa razão, sentimentos de agressão ou depressão também são frequentes nesse periodo, momento 
propicio para a manifestação do bullying enquanto violência. Na faixa etária entre 9 e 11 anos, a criança desenvolve a capacidade de se autoconceituar, ampliando a forma como se veem (PAPALIA; OLDS, 2000; MONTEIRO 2017). Novamente, cabe ressaltar que as influências externas, como a sociedade, as midias e a cultura estabelecida no local de convivência dessa criança, os sistemas bioecológicos, podem moldá-la de forma diferente da descrita.

A autoestima é muito importante nessa etapa do desenvolvimento humano. As crianças ampliam sua capacidade de autoconceito. Uma criança com baixa autoestima tem a tendência de se achar inferior quanto à sua capacidade diante dos outros, comparando-se com seus pares, sentindo-se inadequada. É uma criança como essa que possivelmente será alvo de autores do bullying. Ela também pode julgar a sua própria aparência física ou popularidade. Em geral, o seio familiar é um refúgio para superação dessas dificuldades (PAPALIA; OLDS, 2000; MONTEIRO, 2017). Então, salienta-se a importância da familia e uma dinâmica familiar saudável no contexto social da criança, já que nessa fase do desenvolvimento, ela passa maior tempo no ambiente escolar.

No que concerne aos relacionamentos externos à familia, a amizade e as brincadeiras também são parte essencial e fundamental. As brincadeiras infantis beneficiam o aprendizado e o amadurecimento de habilidades físicas e sociais da criança e a interação significativa, fortalecendo as relações de amizade com outras crianças. Essa interação abre novas perspectivas para o aprendizado de outras relações com a sociedade, além de amadurecer o lado emocional (PAPALIA; OLDS, 2000). Entretanto, existem pontos negativos que envolvem a relação de uma criança com seus pares. A criança busca adequação às regras e normas do grupo de amigos para poder participar. mudando o seu comportamento para ser aceita, como acontece nas mídias e nos grupos sociais, redes sociais digitais com frequência. Essa conformidade é prejudicial quando a criança precisa agir contra seu princípio de julgamento. Assim, nessa perspectiva, o bullying pode se fortalecer, ganhando espaço na vida da criança, sendo utilizado para subjugar o mais fraco e sensivel. O bullying é uma forma de violência que se manifesta com facilidade no ambiente escolar, justamente por se tratar de um desiquilibrio no relacionamento entre as crianças, criando uma amizade fragilizada e desigual (MONTEIRO, 2017).

\section{A abordagem da Teoria Bioecológica do Desenvolvimento Humano}

A Teoria Bioecológica (2011) enfatiza a importância dos ambientes no desenvolvimento humano desde o nascimento e ao longo de sua vida. Inicialmente, as primeiras interações ocorrem no microssistema família. Conforme crescem, essas interações se ampliam e novas situações são introduzidas, aumentando a rede de relações sociais (sistema bioecológico). Assim, a criança passará por mudanças a partir das contribuições de pessoas e do próprio ambiente. Tais transições ecológicas ${ }^{3}$ contribuirão para agregar valores, ideias, crenças e hábitos. Portanto, são nos microssistemas que a criança evidencia seu desenvolvimento humano. Pode-se afirmar que familia e escola são dois contextos importantes para o desenvolvimento da criança (BRONFENBRENNER, 2011; DINIZ; KOLLER, 2010). A escola, em especial, pode tornar-se propícia para a manifestação do bullying, uma vez que há uma maior interação entre pares, podendo acontecer um desequilibrio de poder entre as crianças, gerando violência.

Diniz e Koller (2010) descrevem o afeto como um elemento necessário para o desenvolvimento humano saudável, um processo proximal (BRONFENBRENNER, 2011). O afeto cria vínculos e estabelece relações entre pessoas, e isso mostra a importância deste conceito para a criança, pois para que o desenvolvimento ocorra há a necessidade do outro, do estímulo, dos sentimentos. O desenvolvimento humano é caracterizado por essa interatividade que há

Transição do individuo entre os microssistemas por meio das interações, consolidando relações positivas ou negativas (BRONFENBRENNER, 2011). 
com o outro e com o ambiente e as mudanças duradouras que esse processo proporciona ao longo da vida, iniciadas na infância. Para a Teoria do Desenvolvimento Humano, o desenvolvimento se caracteriza pela capacidade de realizar ações mais complexas em cada dimensão ou na totalidade das dimensões humanas (biopsicossocial) em caráter permanente. Assim, quando a criança aprende um conceito, desenvolve uma habilidade de um estágio simples para um mais complexo, pode-se dizer que houve desenvolvimento. Para Diniz e Koller (2010), cada mudança ocorrida é fruto da interação com o ambiente e com tudo que há nele, contribuindo assim para o desenvolvimento. Por isso, o bullying afeta a criança e traz consequências negativas ao desenvolvimento, ao passo que a interatividade saudável do vínculo com o outro é quebrado por meio da violência que se manifesta.

Com sua teoria, Bronfenbrenner (2011) defende a ideia de um ambiente que interage mutuamente com o individuo e esse, não apenas é influenciado, mas também influencia para que as mudanças aconteçam. Novamente, evidenciase o conceito de processos proximais, em que um ou mais individuos ativos interagem mutuamente com outros indivíduos, objetos ou ambientes em situações peculiares a cada ambiente e etapa do desenvolvimento. Assim, para que esse processo se torne efetivo é necessário que haja uma interação por um período de tempo: o cronossistema. Bronfenbrenner (2011) relata a importância do tempo para organizar de modo sequencial os fatos e contextos históricos ao longo do ciclo vital do ser humano (DINIZ; KOLLER, 2010; BRONFENBRENNER, 2011).

A partir dessas relações estabelecidas com o ambiente e com outros indivíduos é que a criança definirá um modelo de relação interno. Ela desenvolverá as relações de afeto e confiança e suas expectativas de relacionamentos saudáveis ou não (Construção dos sujeitos). Tudo depende de como ela estabeleceu isso na infância. Diniz e Koller (2010, p. 70) mostram que "esse aspecto é importante, na medida em que a qualidade relacional será um importante contributo para o desenvolvimento futuro".

Bronfenbrenner (2011) traz quatro conceitoschave para sua teoria, que permitem a análise do processo de desenvolvimento humano: Processo, Pessoa, Contexto e Tempo (PPCT). O Processo é o padrão estabelecido de interações entre os indivíduos e os ambientes. A Pessoa é o ser humano, individuo que interage modificando e sendo modificado, como uma espiral. O contexto é a influência do ambiente, é o que difere as consequências do desenvolvimento de um individuo para o outro e, por fim, o Tempo, que ordena os fatos cronologicamente.

Portanto, na Teoria Bioecológica, pode-se dizer que o estabelecimento de laços afetivos promove na criança o desenvolvimento da sua capacidade física, social e simbólica. Para a promoção do desenvolvimento pleno, é preciso estabelecer relações interpessoais reciprocas. É nesse envolvimento com o ambiente que ocorre o desenvolvimento. Uma criança segura estabelece relações interpessoais que interagem de tal forma que ela consegue desenvolver a segurança e a autoestima saudável. Uma criança insegura desenvolve relações interpessoais inadequadas (DINIZ; KOLLER, 2010; BRONFENBRENNER, 2011).

Um estudo desenvolvido por Diniz e Koller (2010) mostrou que indivíduos que viveram em ambientes favoráveis tendem a expressar sentimentos positivos, como gratidão, amor ao próximo e interesse pelo outro. Esses sentimentos surgem na infância e crescem ao passo que o ser humano se desenvolve e se torna adulto. O mesmo ocorre em ambientes desfavoráveis, onde a criança convive com sentimentos negativos. Nesse sentido, por meio dessas relações estabelecidas que o ser humano "terá capacidade para se adaptar às exigências, dificuldades e transformações do seu meio" (DINIZ; KOLLER, 2010, p. 74). Ressalta-se a importância das vivências e convivências para o modelo Bioecológico. É por meio dela que o indivíduo apreende novos conceitos do contexto vivido de forma objetiva e subjetiva. Diferentes pessoas terão diferentes experiências em um mesmo contexto dependendo da forma como conduzirão a situação vivida (DINIZ; KOLLER, 2010). 
Considerando crianças que frequentam a escola, grande parte das intervenções feitas nesse ambiente favorecem o seu desenvolvimento como seres humanos. Uma criança tímida, agitada ou agressiva poderá interagir com outros colegas e com seus professores e ser influenciada pelas caracteristicas desses, favorecendo ou inibindo o seu desenvolvimento. Os processos proximais são importantes para o fortalecimento de vínculos por meio do envolvimento com outras pessoas e ambientes que estabelecerão sentimentos e relações interpessoais que ajudarão no desenvolvimento futuro. Portanto, o bullying traz prejuizos ao desenvolvimento pleno do ser humano em sua infância porque impede que haja os vínculos saudáveis para que este processo ocorra de forma harmoniosa.

\section{Metodologia}

Os dados pertinentes a esta pesquisa são de natureza qualitativa e exploratória. A presente pesquisa empírica foi realizada em uma escola municipal $^{4}$, no municipio de Curitiba - Paraná. A seleção do campo de pesquisa foi intencional e se deu pela facilidade de acesso da pesquisadora junto à população pesquisada. Os estudantes selecionados para a participação na pesquisa foram 70 (setenta) crianças do $5^{\circ}$ ano do Ensino Fundamental, entre 9 e 11 anos de idade, de ambos os sexos, do período vespertino, Desse total, 38 (trinta e oito) atenderam o critério de inclusão para participação na pesquisa: trouxeram o Termo de Consentimento Livre e Esclarecido (TCLE) assinado pelo pai/mãe/responsável, sendo, portanto, observados durante as aulas e respondendo a um questionário referente ao bullying, no próprio ambiente escolar, com a ciência da professora regente.

O questionário é composto de 26 perguntas. As 14 primeiras perguntas foram destinadas à caracterização dos participantes (como idade, gênero, familia, gostos pela leitura e escola). Os dados específicos da pesquisa propriamente dita se iniciam com as perguntas fechadas de ordem socioeconômica e contextual do ambiente familiar e social a que as crianças pertencem. 0 objetivo dessas questões é o conhecimento do contexto em que as crianças estão inseridas. As demais perguntas (de 15 a 26) referem-se à percepção delas sobre o bullying e das demais situações de violência física, verbal e emocional, em especial as situações de bullying vivenciadas. São questões abertas que facilitam a escrita da criança a fim de mostrar o ponto de vista dela sobre o assunto em questão. Para este estudo especificamente, utilizou-se apenas a segunda parte do questionário, referente ao bullying. Participaram 16 meninos e 22 meninas.

A análise dos dados qualitativos coletados no questionário foi feita pela técnica de Núcleos de Significação (AGUIAR; OZELLA, 2006). A primeira análise realizada foi possivel após várias leituras flutuantes e a identificação dos pré-indicadores. Seguiu-se com a formulação dos indicadores e dos núcleos de significação. Os núcleos foram construidos de acordo com os "Quatro principiospilares do conhecimento", a saber: Aprender a Conhecer, Aprender a Viver Juntos, Aprender a Fazer e Aprender a Ser, propostos pela UNESCO (2010), pois caracterizam muito bem o que deseja ser exposto na presente análise e discussão dos dados da pesquisa.

\section{Resultados e discussão}

O núcleo de significação Viver juntos tem por objetivo caracterizar a ideia de convivência entre pares, respeitando a diferença do outro. Para criar esse núcleo, utilizou-se do indicador ambiental, uma vez que o ambiente, se inadequado, pode gerar situações violentas ou agressivas, influenciando o comportamento daqueles que estão envolvidos no contexto dele, reforçando os conceitos de Piaget (1994) que baseia a construção da autonomia moral das crianças no cooperativismo e respeito. Na fase da construção da moral, as crianças internalizam os valores morais e norteiam sua forma de pensar a partir da importância e da relevância das regras

\footnotetext{
4 Por questões éticas, optou-se por não citar o nome da escola escolhida como campo de pesquisa, conforme aprovação pelo Comitê de Ética em Pesquisa da UFPR.
} 
colocadas a elas. É no ambiente social e na interação dos pares que a criança construirá os valores, que estão inseridos na família, na escola e na sociedade. Sendo assim, o ambiente escolar é um local propicio para que haja as trocas e interações propostas. (PIAGET, 1994).

Piaget (1994), Vinha e Tognetta (2009) concordam que as interações sociais geram conflitos. Esses autores concebem o conflito como necessário para o desenvolvimento, uma vez que os indivíduos envolvidos em tal ato são motivados por esse desequilibrio a refletirem sobre suas atitudes e restabelecerem a reciprocidade. Notase, porém, que os estudantes autores do bullying não são empáticos ao ponto de perceberem o conflito como positivo, considerando os sentimentos e as perspectivas do outro. No bullying, o ato agressivo é premeditado, portanto, não é um mero conflito.

Percebe-se que nesta faixa etária, entre 9 e 11 anos de idade, os estudantes possuem certas dificuldades em relacionar-se com outros, pela falta de coleguismo ou, até mesmo, pela formação de grupos, chamados de "panelinhas", o que causa, de certa forma, insegurança e instabilidade nas relações de amizade entre as crianças, criando grupos fechados onde outros não podem participar. Isso mostra uma possível falta de empatia e solidariedade, podendo ser considerado como exclusão. Em contrapartida, laços fortes de amizade podem ajudar os estudantes que possuem dificuldades de se sentirem parte de um grupo e de entenderem o conceito de igualdade (SILVA, 2006).

Tognetta (2005) ressalta alguns pontos interessantes inerentes à relação do conflito versus relações harmoniosas, corroborando com os dados apresentados nos núcleos construídos na análise. Relata que por meio do conflito pode-se descobrir quem a pessoa é e o que ela almeja, além de mostrar os traços de empatia. $\bigcirc$ conflito pode ser um caminho para que a criança aprenda a conviver com o outro, servindo para alcançar a autonomia moral, desde que seja entendido, mostrando o ponto de vista e quem ele é, estabelecendo relações harmoniosas com o outro. Por isso, a importância do diálogo entre as resoluções de problemas em sala como forma de prevenção da violência.

Os estudos sobre o ambiente inadequado de formação da criança também corroboram com as pesquisas de Bronfenbrenner (2011), pois "é no contexto dos microssistemas que operam os processos proximais, que produzem e sustentam o desenvolvimento, mas a sua eficácia em implementá-lo depende da estrutura e do conteúdo dos mesmos" (POLLETO; KOLLER, 2008, p. 406). O mesossistema consiste em um sistema ecológico próximo que se relaciona com os ambientes imediatos, como escola e família. As interações acontecem por meio de trocas entre o individuo e o ambiente, seja no aspecto físico, social ou simbólico.

Pode-se associar este primeiro item das significações com o componente Contexto (BRONFENBRENNER, 2011), uma vez que partindo da ideia dos microssistemas, a escola é um ambiente permeado de relações sociais que deveriam ser estabelecidas com reciprocidade e equilíbrio de poder, o que por várias vezes, isso é rompido pelas agressividades mostradas pelos estudantes. As relações são demonstradas por meio de xingamentos e agressões físicas, pela competição entre as crianças. Nota-se que os estudantes tendem a revidar a violência com a própria violência, como forma de "castigar" o outro por ter iniciado a agressão. Isso se mostra nas conversas informais vistas durante a observação realizada pela pesquisadora.

No caso da escola, o ambiente permeado de violência e agressividade tende a promover no individuo ações inerentes a ele. Ressalta-se mais uma vez que o local de maior incidência do bullying é a sala de aula, seguido do recreio, confirmando que as relações entre o ambiente inadequado e as atitudes agressivas dos estudantes em relação aos seus pares fazem sentido. Bronfenbrenner (2011) afirma que nenhuma característica do ser humano pode influenciar de modo isolado, toda e qualquer qualidade ou defeito humano pode encontrar significado e ser expresso dentro de um ambiente.

A discussão do núcleo de significação viver 
juntos está intimamente ligada ao próximo núcleo, o fazer, pois esse segundo foi construido com base nos aspectos morais, com o objetivo de mostrar os julgamentos de valor, as denúncias e delações feitas pelas testemunhas e as diferenças entre os gêneros. O núcleo de significação fazer faz relação com o trabalho em equipe e o aprendizado da convivência com o outro. Piaget (1994) novamente reforça a questão da troca de experiências significativas, a partir dos principios internalizados pela criança, para a construção de uma autonomia e uma identidade moral.

Os estudos de Bronfenbrenner (2011) evidenciam a importância das relações interpessoais no processo de desenvolvimento humano. Ele salienta o mérito das relações entre as pessoas como forma de estabelecer relações recíprocas e para a formação das diades, ou seja, o processo de desenvolvimento de um dos indivíduos contribui para o processo do outro, reforçando os laços de convivência saudável entre os estudantes, no caso do ambiente em questão, a escola. As pessoas com quem a criança interage desempenham um papel importante na formação das estruturas dos processos proximais, que favorecem 0 desenvolvimento das relações interpessoais.

Portanto, na concepção sistêmica (BRONFENBRENNER, 2011), pode-se estabelecer uma relação com o componente Processo, uma vez que as interações entre os individuos partem de caracteristicas individuais e espera-se que esses interajam entre si, em um processo de troca de informações que auxiliem no desenvolvimento. Cada estudante busca uma identidade social dentro do ambiente escolar, fazendo com que adote comportamentos semelhantes de outros integrantes para se sentir parte do grupo. É o que acontece com muitas crianças que são testemunhas do bullying. Outros preferem o isolamento como forma de reflexo ao ato agressivo, caracteristica apresentada por muitos alvos. Alguns estudantes lidam de outra forma e assumem um papel de autores do bullying, muitas vezes, contrário aos seus sentimentos. Usam como uma forma de enfrentamento para a fraqueza que sentem. Por isso, podem ser submissos em seu ambiente doméstico, mas agressivos em outros ambientes, reproduzindo um modelo de comportamento que exerce poder e força.

Em relação aos julgamentos de valor, relacionando com os dados obtidos, podese reafirmar a importância do trabalho com a autoestima dos estudantes, uma vez que a criança que possui baixa autoestima e possivelmente é caracterizada como alvo do bullying desenvolve mecanismos que distorcem os seus sentimentos e a integração ao grupo, ao contrário daqueles que possuem uma autoestima elevada que acreditam e confiam em si mesmos, uma vez que a autoestima é a forma como o indivíduo se vê e como ele mantem relação consigo mesmo, mais comumente como "juizo de valor pessoal". A autoestima também afeta a questão ambiental, uma vez que os com baixa autoestima não persistem em suas tarefas e afetam o status no grupo, este sentimento/emoção, que liga intimamente as relações de agressões psicológicas e verbais do bullying. Os estudos voltados à autoestima são muito relevantes, pois estão relacionadas a consequências negativas como depressão e suicidio e muitas crianças e até adolescentes se engajam em tarefas e comportamentos inadequados como forma de aproximarem-se de algum grupo do qual desejam fazer parte (BANDEIRA; HUTZ, 2012).

Em relação aos alvos, em geral, desenvolvem medo, dificuldade de concentração, depressão, distúrbios psicossomáticos, chegando até mesmo ao abandono dos estudos. Tognetta e Rosário (2013, p. 129) escrevem que "o que lhes falta está relacionado à imagem que têm de si diante do outro; eles se sentem inferiores ao que acreditam ser a determinação das qualidades do grupo ao qual pertencem". Durante as observações, pode-se notar estudantes que possuem poucos amigos e são introvertidos. Essas caracteristicas corroboram com os estudos realizados por Lopes Neto (2005) que identificam algumas caracteristicas possiveis dos alvos, que os tornam mais vulneráveis às ações dos autores de bullying, como por exemplo, diferenças físicas ou emocionais. 
Portanto, pode-se pensar que o conceito de violência está sendo incorporado nesses estudantes com valores equivocados, ou seja, elas estabelecem "julgamentos heterônomos nos quais o sujeito não consegue se colocar no lugar do outro e se comover com sua dor" (TOGNETTA; ROSÁRIO, 2013, p. 112). Nesse mesmo estudo, apenas $8,8 \%$ dos estudantes entrevistados observaram valores morais nos outros; enquanto $17,9 \%$ enxergam apenas valores individualistas. Isso mostra que os estudantes possuem pouca empatia pelo outro e não conservam valores, como relata Piaget (1994) em sua teoria sobre o desenvolvimento moral.

O núcleo de significação ser tem o objetivo de valorizar o ser crítico e intelectual, um ator responsável. Isso ressalta a importância da formação da criança como um cidadão crítico, que respeita e aceita o outro com suas diferenças. Esse núcleo foi baseado nos dados voltados às caracteristicas emocionais e aos estereótipos estéticos. Nota-se que também faz íntima relação com os demais núcleos citados. Tognetta e Vinha (2009) trazem um alerta sobre a disseminação do bullying nas escolas, que envolvem a formação da identidade pessoal. Explicam que os grandes vilões para as manifestações do bullying são os próprios estudantes, uma vez que são eles que precisam construir a sua personalidade, por meio da integração dos valores e principios que traduzam as experiências que foram passadas e aquelas que se pretendem atingir, para assim, tornaremse resilientes e formarem uma imagem de como se veem e como querem ser vistos pelos outros.

Portanto, para se analisar o bullying através da diferença dos gêneros ou questões étnicoraciais, deve-se considerar os padrões culturais impostos pela sociedade que, inclusive, criam expectativas diferentes sobre o comportamento das meninas e dos meninos ou até mesmo os estigmas criados como estereótipos sociais que classificam as pessoas de acordo com um modelo pré-estabelecido, que dissolve a real identidade do individuo (BATISTA, 2013). Espera-se dos meninos um temperamento forte e agressivo, enquanto meninas precisam ser frágeis, delicadas e obedientes, ou estabelecendo as diferenças entre "ser branco" e "ser negro", naturalizando e fixando as posições sociais e raciais. Por isso, a questão ambiental, novamente apresentada aqui por meio do núcleo de significação viver juntos e a diferença entre os gêneros e raça do núcleo fazer são evidenciadas, justamente porque a criança aprende os comportamentos típicos de cada gênero por meios dos modelos masculinos e femininos em seus contextos de convívio e por meio das representações estabelecidas pela sociedade sobre determinado assunto (BINSFELD; LISBOA, 2010).

Além disso, pode-se reforçar a ideia de que todos os envolvidos em situações de agressão (alvos, autores ou testemunhas) podem ser vitimas de um ambiente violento. Os autores, por exemplo, se mostram vulneráveis uma vez que tendem a reproduzir aquilo que vivenciam em seus contextos. Mesmo que os autores do bullying pareçam estar contentes sendo os "valentões", supõe-se que os mesmos podem sofrer com atitudes violentas em casa ou até mesmo sendo reforçados pelos colegas para permanecem nesse papel, já que o bullying é considerado um fenômeno decorrente da interação social, correlacionando com os estudos da Teoria Bioecológica (BINSFELD; LISBOA, 2010; BRONFENBRENNER, 2011).

A relação desse item, portanto, pode ser feita com o componente Pessoa (BRONFENBRENNER, 2011), uma vez que demonstra as caracteristicas individuais de cada um e os seus comportamentos, mostrando a fragilidade e a vulnerabilidade frente à interação com os outros. No entanto, os componentes Tempo e Contexto também são importantes e relevantes para se compreender a questão, já que amplia o olhar sobre o fenômeno bullying como um todo. No componente Tempo, pode-se pensar no ciclo de violência vividos por cada estudante, revelado por meio das relações dos ambientes de contato (familia, escola, entre outros). A dinâmica que se estabelece entre esses contextos de interação permite que possamos, ao longo do tempo, observar situações de violência na vida dos estudantes e o grau de influência das mesmas. 
O núcleo de significação conhecer tem por objetivo valorizar a importância do aprender. A construção desse núcleo se deu pela formação do conceito e tipologia do bullying e os tipos de violência encontrados no ambiente escolar. A maioria dos estudantes entende de forma geral o que é o bullying e do que ele trata, mas ainda há certa fragilidade no real conceito sobre o fenômeno.

Aqui, ressalta-se mais uma vez a importância da sensibilização em relação ao fenômeno de forma geral, pois ainda é visto como algo comum e tido como "brincadeiras da idade", confirmando os estudos de Fante (2005), que insiste em uma formação continuada dos profissionais da educação e da comunidade escolar em geral sobre o bullying.

Pode-se estabelecer nesse fator uma relação com os quatro componentes da concepção sistêmica (modelo PPCT) uma vez que os mecanismos de prevenção precisam ser eficazes com a Pessoa em sua individualidade e comportamento, enxergando o outro com respeito e empatia acima de tudo; isso acontecerá dentro de um Processo estabelecido pela instituição; - Contexto escolar precisa estar adequado e aberto às práticas educativas de prevenção e às mudanças ocorridas e isso dentro de um período de Tempo (BRONFENBRENNER, 2011).

Novos projetos e estudos que aprofundem o conceito e as características do fenômeno, a fim de promover entendimento e conscientização em relação ao bullying e às diferenças de gênero precisam ser apresentados às crianças. As estratégias para minimizar as ações desse tipo de agressão na escola necessitam de comprometimento e investimento no mesossistema familia-escola, adotando condutas adequadas para reduzir a violência de forma eficaz (BANDEIRA, 2009).

\section{Considerações finais}

Não se pode negar a relação intrínseca bullying vs. valores humanos. Uma sociedade que demonstra violência em sua construção cultural tende a naturalizar as ações agressivas entre os indivíduos e, por isso, muitas vezes não entendidas como violência. Há uma tendência social de justificar o bullying escolar como brincadeira de criança, sem maldade, retardando a identificação precoce de um fenômeno onde não há vencedores, onde todos perdem. Nesse sentido, a escola e a sociedade em geral, precisam analisar as raizes culturais do bullying, rever seus conceitos, principios e valores, a fim de estabelecer metas e mecanismos de prevenção. A falta de compreensão dos valores éticos, de respeito, de diversidade, de generosidade, de afeto e tantos outros, banaliza o bullying, deixando-o como "normal", ou até mesmo como uma fase a ser vivida pelo estudante em sua infância, para poder superá-la.

A Teoria Bioecológica do Desenvolvimento Humano (BRONFENBRENNER, 2011) propicia se compreender o bullying como um fenômeno sistêmico e relacional que influencia e é influenciado por sistemas ecológicos imbricados e interdependentes. Por ser ainda considerado "brincadeiras da idade" em muitas formas de violência e agressão, nem sempre são identificados como bullying. É fundamental a investigação e diagnóstico do fenômeno nas escolas e a sua repercussão na vida das crianças, para que se possa caracterizar e verificar a incidência e a abrangência do bullying. Portanto, nesse sentido, pode-se considerar que todos os envolvidos no fenômeno bullying são vitimas, pois se verifica que mesmo o autor, em muitos casos, sofre da mesma violência em seu microssistema familiar ou social, reproduzindo aquilo que vivencia como forma de minimizar sua dor. Assim, não há dualidade entre autor/alvo.

No modelo PPCT, proposto pela Teoria Bioecológica, os processos envolvem as conexões exercidas pela pessoa que está em desenvolvimento constante, seu histórico de organização e adaptação nas diferentes transações ecológicas. Para ocorrer o desenvolvimento, há a necessidade de uma participação ativa em interações (tanto com outros individuos bem como com os ambientes imediatos), dentro de um período de tempo. Aqui, pode-se também citar os processos proximais, nos quais os individuos interagem face a face, sendo a interação recíproca. 
Buscou-se, também, verificar algumas possiveis influências do ambiente sociomoral (PIAGET, 1994) na prática do bullying, como a construção de uma autonomia moral nos estudantes como forma de lidar com as agressões de forma solidária e cooperativa, resolvendo seus próprios conflitos, sem que, para isso, busquem a violência como forma de resolução de problemas. Portanto, a importância de se promover conteúdos curriculares no que tange as temáticas voltadas à paz, ao respeito, à solidariedade, são importantes. Segundo essa teoria, os individuos precisam desenvolver o senso de justiça, de autonomia e de reciprocidade a fim de que resolvam seus conflitos de forma assertiva, por meio de relações interpessoais cooperativas e respeitosas. Portanto, a forma como estudantes e professores, bem como a comunidade escolar em geral, agem diante de um ato agressivo ou do bullying influencia a maneira como os indivíduos vão lidar com a situação. Assim, o ambiente onde ocorrem essas interações é chamado de ambiente sociomoral. Se o ambiente sociomoral é cooperativo, as relações são pautadas no respeito e cooperação e por isso proporcionam uma forma mais branda de se resolver conflitos entre pares.

Sendo assim, as escolas, de modo geral, devem atentar para a qualidade das relações entre os estudantes, para que dentro de um ambiente assertivo e construtivo, possam desenvolver formas assertivas e sadias de lidar com os conflitos, uma vez, que havendo uma sensibilidade moral adequada, a criança desenvolva sentimentos de empatia, diminuindo assim práticas como o bullying nas escolas.

Observou-se que os estudantes possuem dificuldades em perceber a dor e o sofrimento no outro, bem como a ocorrência do bullying envolvendo terceiros, mais do que em si próprios. Acredita-se que isso aconteça pela falta ou a inadequação do desenvolvimento moral na criança, fazendo com que ela não consiga enxergar o outro e, assim, não senta a empatia necessária para ajudar em uma situação violenta. Por isso, pode-se constatar que o bullying é um problema também de ordem moral, uma vez que as crianças aparentam demonstrar certa insensibilidade em relação ao outro. A preocupação que se instala enquanto pesquisadora é de pensar que a violência pode estar criando uma sensação de banalização e naturalização do fenômeno e sendo assim, as crianças não conseguem perceber o bullying efetivamente, bem como qualquer ato agressivo contra o outro individuo como uma situação grave, mas a veem como natural e comum.

O bullying na escola apresenta-se de forma diferenciada entre os gêneros. A pesquisa mostrou que as meninas são mais propensas a disseminar o bullying indireto e os meninos o bullying direto, em especial, a agressão física. Isso merece aprofundamento para evitar o reforço da 'supremacia' da força masculina sobre a 'fragilidade' do gênero feminino (construção dos sujeitos) (BABIUK; FACHINI; SANTOS, 2013).

Ressalta-se a necessidade da criação de programas de prevenção efetivos que priorizem uma cultura de paz nas escolas e elaboração de possiveis mecanismos de intervenção ao bullying, uma vez que as consequências do fenômeno são para todos os envolvidos na comunidade escolar, considerando, assim, o bullying como um fenômeno sistêmico que atinge proporções elevadas. Então, ao pensar em projetos que tentem minimizar ou "sanar" o bullying nas escolas é necessário que se envolva toda a comunidade escolar, justamente porque o processo de minimização do fenômeno envolve as pessoas e os ambientes, partindo, assim, sob o ponto de vista da Bioecologia. Logo, é necessário ter um olhar sobre os fatores que levam os estudantes a terem atitudes agressivas, identificando problemas interpessoais, partindo do pressuposto da análise dessas relações e dos seus ambientes, como sistemas interdependentes. Cabe lembrar que o ambiente escolar, como microssistema, deve ser agradável e acolhedor, onde os estudantes se sintam seguros para expressarem suas dificuldades em busca de auxilio e possam ser atendidos.

Sob a luz da teoria sociomoral, é preciso que a escola trabalhe com a sensibilização e com a conscientização de um ambiente acolhedor e 
com um bom clima moral, para contribuir com uma qualidade das relações interpessoais na escola. A escola como um todo precisa refletir sobre as condutas e sobre a forma como as interações sociais estão ocorrendo em seu interior, para promover políticas de prevenção e intervenção efetivas, que trabalhem e estimulem os estudantes a viverem de forma cooperativa.

\section{Referências}

AGUIAR, Wanda Maria Junqueira; OZELLA, Sérgio. Núcleos de Significação como instrumento para a apreensão da constituição dos sentidos. Psicologia, Ciência e Educação, Brasilia, n. 26, p. 222-245, 2006. https://doi.org/10.1590/S1414-98932006000200006.

BANDEIRA, Cláudia de Moraes. Bullying: autoestima e diferenças de gênero. 2009. 69f. Dissertação (Mestrado em Psicologia) - Universidade Federal do Rio Grande do Sul, Porto Alegre, 2009

BANDEIRA, Cláudia de Moraes; HUTZ, Claudio Simon. As implicações do bullying na autoestima dos adolescentes. Revista Semestral da Associação Brasileira de Psicologia Escolar e Educacional, São Paulo, v. 14, n. 1, p. 131-138, 2010. https://doi. org/10.1590/S1413-85572010000100014.

BABIUK, Graciele Alves; FACHINI, Flávia Granzotto; SANTOS, Gabriel Nappi. Violência de gênero nas escolas: implicações e estratégias de enfrentamento. In: CONGRESSO NACIONAL DE EDUCAÇÃO - EDUCERE, 2013.

BATISTA, Elise Helena Morais. Bullying e preconceitos étnico-raciais. Poiésis, Tubarão, v. 7, n.12, p 302-323, 2013. https://doi.org/10.19177/prppge. v7e122013302-323.

BINSFELD, Adriana Raquel; LISBOA, Carolina Savaiva de Macedo. Bullying: Um estudo sobre papéis sociais, ansiedade e depressão no contexto escolar do Sul do Brasil. Interpersona, [s. l.], v. 4, n. 1, p. 74-105. 2010. https://doi.org/10.5964/ijpr.v4i1.44.

BRONFENBRENNER, Urie. Bioecologia do desenvolvimento humano: tornando os seres humanos mais humanos. Tradução: André de Carvalho Barreto. Porto Alegre: Artmed, 2011.

DINIZ, Eva; KOLLER, Silvia Helena. O afeto como processo do desenvolvimento ecológico. Educar em Revista, Curitiba, n. 36, p. 65-76, 2010. https://doi. org/10.1590/S0104-40602010000100006.

FANTE, Cléo. Fenômeno bullying: como prevenir a violência nas escolas e educar para a paz. Campinas: Verus Editora, 2005.

LOPES NETO, Aramis Antônio. Bullying - comportamento agressivo entre estudantes. Jornal de Pediatra, Rio de Janeiro, v. 81, n.5, p. 164-175, 2005. https:// doi.org/10.1590/S0021-75572005000700006.

MOREIRA, Marco Antônio. Teorias de aprendizagem São Paulo: EPU, 1999
MONTEIRO, Michelle Popenga Ggeraim. O bullying segundo a percepção dos estudantes do $5^{\circ}$ ano do ensino fundamental. 2017. 148f. Dissertação (Mestrado em Educação) -- Universidade Federal do Paraná, Curitiba, 2017

OLIVEIRA, Josi Rosa; GOMES, Magda Altafini. Bullying: reflexões sobre a violência no contexto escolar. Educação por Escrito, Porto Alegre, v. 2, n. 2, p. 1-13, jan. 2012.

PAPALIA, Diane; OLDS, Sally Wendkos. Desenvolvimento humano. Porto Alegre: Artes Médicas Sul, 2000.

PIAGET, Jean. O juizo moral da criança. Tradução: Elzon Lenardon. São Paulo: Summus, 1994.

POLETTO, Michele; KOLLER, Silvia Helena. Contextos ecológicos: promotores de resiliência, fatores de risco e de proteção. Estudos de Psicologia. Campinas. v. 25, n. 3, p. 405-416, 2008. https://doi. org/10.1590/S0103-166X2008000300009.

SILVA, Dezir Garcia. Violência e estigma: bullying na escola. 2006. 136f. Dissertação de (Mestrado em Ciências Sociais) - Universidade do Vale do rio Sinos, São Leopoldo, 2006

TIMM, Jordana Wruck. Bullying: o principal vilão da boa convivência. (In) Formando uma equipe para o êxito! Educação por Escrito, Porto Alegre, v. 2, n. 2, p. 16-24, jan. 2012

TOGNETTA, Luciene Regina Paulino. A construção da solidariedade e a educação do sentimento na escola: uma proposta de trabalho com virtudes numa visão construtivista. Campinas: Mercado das Letras, 2003.

TOGNETTA, Luciene Regina Paulino. Violência na escola: os sinais de bullying e o olhar necessário aos sentimentos. In: Pontes, Aldo; De Lima, Valéria Scomparim. Construindo saberes em educação. Porto Alegre: Editora Zouk, 2005.

TOGNETTA, Luciene Regina Paulino. A formação da personalidade ética: estratégias de trabalho com afetividade na escola. Campinas: Mercado das Letras, 2013

TOGNETTA, Luciene Regina Paulino; ROSÁRIO, Pedro. Bullying: dimensões psicológicas no desenvolvimento moral. Est. Aval. Educ., São Paulo, v. 24, n. 56. p. 106-137, set./dez. 2013. https://doi.org/10.18222/ eae245620132736.

TOGNETTA, Luciene Regina Paulino; VINHA, Telma Pileggi. Estamos em conflito, eu comigo e com você: uma reflexão sobre o bullying e suas causas afetivas. Santa Maria: Ed. Da UFSM, 2009.

UNESCO. Cultura de paz: da reflexão à ação; balanço da Década Internacional da Promoção da Cultura de Paz e Não Violência em Beneficio das Crianças do Mundo. Brasilia: UNESCO; São Paulo: Associação Palas Athena, 2010. 256 p. 
Michelle Popenga Geraim Monteiro

Doutoranda e Mestra em Educação pela Universidade Federal do Paraná (UFPR, Curitiba, Paraná, Brasil). Especialista em Neuropedagogia. Graduada em Pedagogia. Bolsista CAPES.

\section{Araci Asinelli-Luz}

Doutora em Educação pela Universidade de São Paulo (USP, São Paulo, São Paulo, Brasil). Professora associada do setor de educação da Universidade Federal do Paraná (UFPR, Curitiba, Paraná, Brasil).

\section{Endereço para correspondência}

Michelle Popenga Geraim Monteiro

Universidade Federal do Paraná

Rua General Carneiro, 460, $2^{\circ}$ andar

Rua Rockfeller, 57, $2^{\circ}$ andar, sala 239

Campus Rebouças, 80060-150

Curitiba, PR, Brasil

Araci Asinelli-Luz

Universidade Federal do Paraná

Rua Rockfeller, 57, $2^{\circ}$ andar, sala 239

Rua General Carneiro, 460, $2^{\circ}$ andar

Campus Rebouças, 80060-150

Curitiba, PR, Brasil 